\title{
Determining the age of documents based on the stamp and seal impression
}

\author{
Miroslav BusarČEvić \\ Private court expert, Serbia \\ BRANISLAV SimONOVIĆ \\ ORCID: 0000-0002-3445-0320 \\ Faculty of Law, University in Kragujevac, Serbia
}

\begin{abstract}
The present article discusses determining the age of a document based on a comparative analysis of the stamp impression in the questioned documents and an authentic document. The aim of the paper is to show that classical traceology methods are easily applied in judicial practice. Based on the analyzed instances of judicial practice, the main conclusion of the paper is that typical analysis of the stamp impression can precisely show the time frame for when the questioned document was created - no expensive and complex physicochemical laboratory analysis methods are necessary.
\end{abstract}

Keywords: determining the age of the document based on the stamp impression, comparative analysis of the stamp impression, general, individual, and identifying characteristics

\section{Introduction}

Forensically determining the validity of documents is important in modern society. The documents are essential in almost all segments of our lives - nearly everything important that happens to us or that we do. The 
first crucial document in our life is our birth certificate, and the last - our death certificate. Between those two points of our lives, there are numerous documents, such as: contracts, checks, bonds, loans, tax reports, or wills. The validity of those documents can sometimes be questionable; in those cases it is a subject of experts' analysis before the court. ${ }^{1}$

One of the major challenges in forensic practice is determining the age of documents. The obtained results lead to reliable conclusions neither in the cases when the absolute age of the document is being determined (determining the time when the document was created) nor in cases when relative age of the document is being determined (which of the two documents is older, the chronology of certain written parts of the document, adding certain letters or numbers, backdating, etc.). This applies to simple microscopic methods, diffusion techniques, and methods using more advanced technologies, such as Raman spectroscopy, electrostatic examination, scanning, and confocal microscopy. ${ }^{2}$

In scientific and scholarly literature, the most frequently published papers are those which talk about the methods of determining the age of a document based on the ink analysis (ballpoint pens) used during document creation. They present the reliability of different methods, mostly physicochemical methods. Until now it has not been possible to determine the exact age of a document based on the ink analysis. ${ }^{3}$ The conditions in which a document was stored affect the chemical properties of the ink, which further complicates the use of a physicochemical method in for-

1 R.L. Brunelle, K.R. Crawford, Advances in the forensic analysis and dating of writing ink, Springfield, IL 2003.

2 M. Goc, M. Miron, "Examination of the relative age of documents. Part I. Methods of examining the sequence of writing made using different techniques on a paper substrate - general issues", Problemy kryminalistyki (Issues of Forensic Science) 284, 2014, no. 2, pp. 1-4.

3 For example: R.L. Brunelle, K.R. Crawford, op. cit.; G.M. LaPorte et al., "The identification of 2-phenoxyethanol in ballpoint inks using gas chromatography/mass spectrometry - relevance to ink dating", Journal of Forensic Science 49, 2003, no. 1, pp. 1-5; S. Lociciro et al., "Dynamic of the ageing of ballpoint pen inks: quantification of phenoxyethanol by GC-MS" Science \& Justice: Journal of the Forensic Science Society 44, 2004, no. 3, pp. 165-171; J.H. Bügler, H. Buchner, A. Dallmayer, "Age determination of ballpoint pen ink by thermal desorption and gas chromatography-mass spectrometry", Journal of Forensic Sciences 53, 2008, no. 4, pp. 982-988. 
ensics. ${ }^{4}$ Apart from that, experiments show that different treatments of a document (exposure to a high temperature or strong light) artificially accelerate the aging of the ink and the document. After such treatments, the use of standard physicochemical methods will result in conclusions that a document is older than it is in reality. ${ }^{5}$ When talking about challenges of determining the age of a document by using the physicochemical method of ink analysis, we also refer to a paper by Deviterne-Lapeyre ${ }^{6}$ as well as more recent literature.

Fewer papers were published on the methods of determining the age of a document based on the analysis of the age of paper. The research subject here are the absolute and the relative ages of a document - that is, a paper document. It appears that in forensic practice determining the relative age of a document is more common than determining its absolute age (except in wills and some contracts). However, the prevailing opinion in literature is that determining the age of a document based on the physicochemical paper analysis method cannot fulfill the requirements of the modern judiciary - that is, numerous challenges are faced during such research. ${ }^{7}$ In cases of determining the age of documents based on the paper analysis,

${ }^{4}$ O.A. Skoromnikova, R.A. Yurova, E.A. Stepanenko, “Актуальные проблемы применения методики «Определение давности выполнения реквизитов в документах по относительному содержанию в штрихах летучих растворителей»” (Ongoing issues with the use of the ink dating methodology based on relative content of volatile solvents in document entries), Теория и практика судебной экспертизы (Theory and Practice of Forensic Science) 13, 2018, no. 3, pp. 128-131.

${ }^{5}$ C. Weyermann, B. Spengler, "The potential of artificial aging for modelling of natural aging processes of ballpoint ink", Forensic Science International 180, 2008, pp. 23-31.

${ }^{6}$ C.M. Deviterne-Lapeyre, "Interpol review of questioned documents 2016-2019", Forensic Science International: Synergy 2, 2020, pp. 429-441.

${ }^{7}$ For example: R. Kumar, V. Kumar, V. Sharma, "Fourier transform infrared spectroscopy and chemometrics for the characterization and discrimination of writing/photocopier paper types: Application in forensic document examinations", Spectrochimica Acta. Part A: Molecular and Biomolecular Spectroscopy 170, 2017, pp. 19-28; L. Ortiz-Herrero et al., "Direct and indirect approaches based on paper analysis by Py-GC/ MS for estimating the age of documents", Journal of Analytical and Applied Pyrolysis 131, 2018, pp. 9-16; C.S. Silva et al., "Chemometric approaches for document dating: Handling paper variability”, Analytica Chimica Acta 1031, 2018, pp. 28-37; C.M. Deviterne-Lapeyre, op. cit. 
published articles show that due to the conditions in which the documents were stored and various manipulations performed on the paper (such as exposure to light, heat, chemicals), the use of standard physicochemical methods will result in conclusions that a document is older than in reality. ${ }^{8}$ There are also published papers based on the physicochemical methods in which the authors tried to find an answer to the question whether or not there was any artificial aging of a particular document. ${ }^{9}$

The smallest number of papers is dedicated to determining the age of a document based on the stamp impression. They describe physicochemical methods of using ultraviolet visible spectrophotometer ${ }^{10}$ or Raman spectroscopy and gas chromatography ${ }^{11}$ when studying the paper's ink absorption at the moment of impression. Those experimental studies are done in strictly controlled conditions and their implementation represents a great challenge for the modern judiciary when it comes to different types of ink, paper, or conditions under which certain documents were stored and possibly mechanically altered.

The observations based on the three types of characteristics which can be seen on the stamp and its impressions on paper are of particular interest not only for this paper, but also for the practical implementation of

8 J. Zięba-Palus et al., "Analysis of degraded papers by infrared and Raman spectroscopy for forensic purposes", Journal of Molecular Structure 1140, 2017, pp. 154-162.

9 K.O. Gorshkova, “Выявление признаков искусственного старения документов: исследование сигналов флуоресценции оптических отбеливателей с поверхности бумажного носителя" [Identification of signs of artificial aging of documents: study of fluorescence signals of optical brighteners from the surface of a paper carrier], Современные тенденции развития науки и технологий Сборник научных трудов по материалам Вмеждународной научно-практической конференщии, г. Белгород [Modern trends in the development of science and technology: Collection of scientific papers based on the materials of the International scientific and practical conference in Belgorod], 31.08.2015, https://mepk-a.ru/bez-rubriki/vyyavlenie-priznakov-iskusstvennogo/.

10 G. Ouyang et al., "Preliminary studies on the absorbance ratio method used to determining the age of stamp-pad ink seal", Journal of Forensic Sciences 64, 2019, no. 4, pp. 1203-1212.

11 V.A. Kochemirovskiy et al., "Age determination of handwritten inscriptions and stamp impressions on documents using Raman spectroscopy and gas chromatography", News of Science. Proceedings of Materials the International Scientific Conference, Czech Republic, Karlovy Vary - Russia, Moscow, 30-31 August 2015, pp. 16-24, https://mepk-a. ru/bez-rubriki/age-determination-of-handwritten/. 
stamp impression analysis in determining the age and possible forgery of a document. Firstly, there is possible damage which can occur during the manufacturing process, resulting in specific impressions the stamp leaves on the paper. Secondly, small damage can happen due to its use or misuse, including: worn letters and numbers, damaged rim, cuts - due to the low quality material used in its manufacturing - and some additional changes within the stamp, all of which can be significant in determining the authenticity of the stamp and possible forged documents. These changes have been described as bubbles, lumps in the surface, loose "fins" of rubber caused by defects in the molding, trimmed edges of the stamp's rubber base, etc. The third type of traces visible in a document during the stamp impression is caused by the accumulation of dirt, particles gathered in the crevices between the letters and numbers, or even a hair intertwined between letters. These changes are important for following the time sequence of the stamp impressions - they indicate the group and individual characteristics seen on a stamp. The significance of its individual characteristics affecting the impression is particularly emphasized. Forensic investigations of that type include comparative analysis, the use of microscopes, and enlarged photographs of the stamp impression. ${ }^{12}$

This paper presents the method of determining the age of a document based on the stamp and seal impression, used by independent expert witness Miroslav Busarčević for many years. The method is based on a comparative analysis of traces by using the magnifying equipment (stereo microscopes, enlarging the stamp impression photo on the computer screen). The characteristic of Busarčević's method is seen not only in the implementation and reliability of the proof in his experimental research, but also in real practice of forensic expertise and defense of the obtained results in the court of law.

Miroslav Busarčević has been employed as a professional police expert, currently court expert, in National Forensic Center at the Ministry of Internal Affairs since 1971. While conducting research on the issue of determining the age of documents, he developed the method for determining their exact age based on the stamp/seal impressions.

12 Scientific examination of questioned documents, eds. J.S. Kelly, B.S. Lindblom, Boca Raton, FL 2006, pp. 258-263; D. Ellen, S. Day, C. Davies, Scientific examination of documents: methods and techniques, Boca Raton, FL 2018, pp. 176-178. 


\section{Theoretical basis for the method of determining the age of a document based on a comparative analysis of the stamp impression}

When talking about stamps and seals, one should always bear in mind the tridimensional rubber part used for making ink impressions on the paper. A well-known fact in criminal forensics is that every stamp or a seal contains general and individual characteristics. General (also known as group) ones are its shape and size, along with the disposition, shape, and size of its certain elements. The general characteristics of the stamp and seal in their impressions on the paper, whether whole or partial, are always made as an image in the mirror and represent the general characteristic of the impressions made. Observation of these characteristics is used exclusively for elimination, to narrow the choice of the stamps and/ or seals from which the impressions can (but do not necessarily) originate.

It is known that the individual characteristics of the stamp and seal are accidental (tridimensional) damage on the letters and other elements of the relief, visible to the naked eye or with a microscope. Some of the damage with stamps or seals can occur during manufacture due to a (tolerable) mistake, some can be created during the use (wearing) as well as by external factors, especially heat ${ }^{13}$ which, although slowly, can change the shape and dimensions of the stamp/seal. Some damage can disappear completely or new ones can be created, which all depends on the way the stamp/seal is stored and used. Individual characteristics of a given stamp or seal are unique and at any given moment distinguish the stamp/seal from others (for example forged ones) which can possess the same general characteristics.

However, individual characteristics of a stamp/seal can also be: temporarily stuck dirt and specks of dust, tiny hairs, and fibers of the textile or of other origin, which after few of the consecutive impressions can fall off the stamp/seal but they may stay on them for a longer period of time as well.

13 Considering the heat tolerance of the relatively hard rubber into which the profile of a seal or stamp has been engraved. 
Additionally, if the ink was applied only once to the stamp/seal's rubber surface, after which two or more consecutive impressions were made, one possible outcome is that some of the impression elements show damage of a matching or similar recognizable shape, made as a result of an uneven spreading of the ink along the surface of a stamp/seal. In such cases, damage created in the impressions have the same significance as the other individual characteristics of the stamp/seal.

Unlike the general characteristics of a stamp/seal, the individual ones in the consecutive impressions on paper can be various and specific but always in recognizable two-dimensional shapes, whether they are visible to the naked eye or only with the help of the optical magnifier and stereo-microscope. However, nowadays, the examination using the optical magnifier and stereo-microscope of the stamps/seals has been quite successfully replaced with scanning resolution of $1200 \times 2400$ pix/inch and photo editing in any of the Adobe Photoshop software versions - especially since it is currently an inevitable tool in presenting the results.

The two-dimensional reflection of individual characteristics of a stamp/ seal in their impressions is called the "identifying characteristics" 14 by Busarčević because of their importance in the identification process. Their presence in the stamp/seal impressions with the same general characteristics represents, without a doubt, material evidence that they were made with the same stamp/seal. For a precise identification of a certain stamp/ seal it is necessary that they, besides the shared general characteristics, contain at least one clearly recognizable individual characteristic present at the same spot.

Due to the different ways they are created, the origin of the identifying characteristics in the impressions of the stamp/seal, even though they objectively exist, can be questionable, especially if they are repeated in a few consecutive impressions of the same stamp/seal and there is no indication of their origin. Basically, only the damage in the stamps/ seals whose position and recognizable shape are consecutively repeated in two or more impressions has the status of identifying characteristics, no matter how it was created. There can appear a mismatching in size

${ }^{14}$ It in general applies to all the imprints (for example, shoes, car tires, etc.), no matter what surface they are on. 
due to a possible difference in the pressure strength and the angle the impressions were made with.

There is no impression of a stamp/seal whose optic examination cannot show at least one or more different signs of damage in their content, macroscopic as well as microscopic. Those signs can produce identifying characteristics of the impression. However, even though noticed damage can potentially become identifying characteristics, that can only be determined during the comparative analysis of other impressions of the same stamp/seal. On the other hand, the fact that changes of individual characteristics of the stamp/seal are necessarily reflected in the changes of the identifying characteristics of the impression enables us to determine the exact time the changes occurred. That fact served as the base for Busarčević's method of identifying the age of a document which contains the impression of a stamp/seal. The successful implementation of this method is directly affected by the number of documents used for comparison. Documents used for comparison should contain the impressions of the same stamp/seal as those in the questioned document(s) and they should originate from the same time period, including the date on the questioned document(s). For such purposes, only the original copies of the documents in question can be used, along with the original copies of the ones used for the purpose of comparing.

\section{Examples of case studies presented before the court}

This work will present three of many Busarčević's cases in which he used the mentioned method for determining the age of a document.

\section{Case Number 1}

In 2005 in one court proceeding two documents made in memorandum of a private company for manufacturing and exporting the industrial equipment needed to be checked and the real time of their making needed to be determined.

The first document is a receipt on a foreign currency loan from a person employed at the same company, dated 10.09.1995, containing the signature of the company's owner and the company's stamp impression. 
The second document was the relationship agreement on the loan, dated 15.04.1997, containing the signatures of the lender - plaintiff in the case, and the previously mentioned company owner, along with the company's stamp impression. The text in the questioned receipt was written in Latin letters and Arabic numbers on the typewriter, and the agreement was written on a personal computer also in Latin letters and Arabic numbers, but in italics, and printed. According to the relationship agreement, the total sum was 1,328,947 DM. Both documents first appeared approximately in 2003, a year after the company owner, whose signature was on the receipt, died in a car accident.

In the court proceeding, the defendant, widow of the deceased company owner, stated that her late husband had never taken any loans from any individuals or the plaintiff, and that he had not made any relationship agreement on the loan. She claimed that her husband had immense trust in the plaintiff who, as an old friend, was given a job at the company. For the purposes of ordering supplies necessary for the production, the plaintiff was given the company's blank memoranda which, in the bottom right corner, held the signature of the owner and the stamp impression of the company. She also stated that the plaintiff abused that privilege and used two of the memoranda to make a false agreement and the receipt. She added that from the moment the company was founded, only PCs were used for financial transactions and that there was no need for her husband to use the typewriter which they had not even possessed.

Figure 1 shows the general layout of the original samples on both the questioned documents, and Figure 2 shows a closer look on the company owner's signatures with a stamp impression of the company.

Comparative optical analysis of the stamp impression in the questioned receipt and questioned agreement showed that they are matching as far as the general characteristics are concerned - these being the shade of purple of the stamp ink impressed, the size ${ }^{15}$ and the width of the double circle along with the joined disposition shape and size of the content elements (Latin letters, quotation marks, a Roman number and a six-pointed star). It has also been stated that in the same places both impressions possess

15 Whenever the size of the stamp is concerned, especially its rubber relief surfaces, the possible deviation that depends on the pressure and the angle the impression was made with should always be taken into consideration 


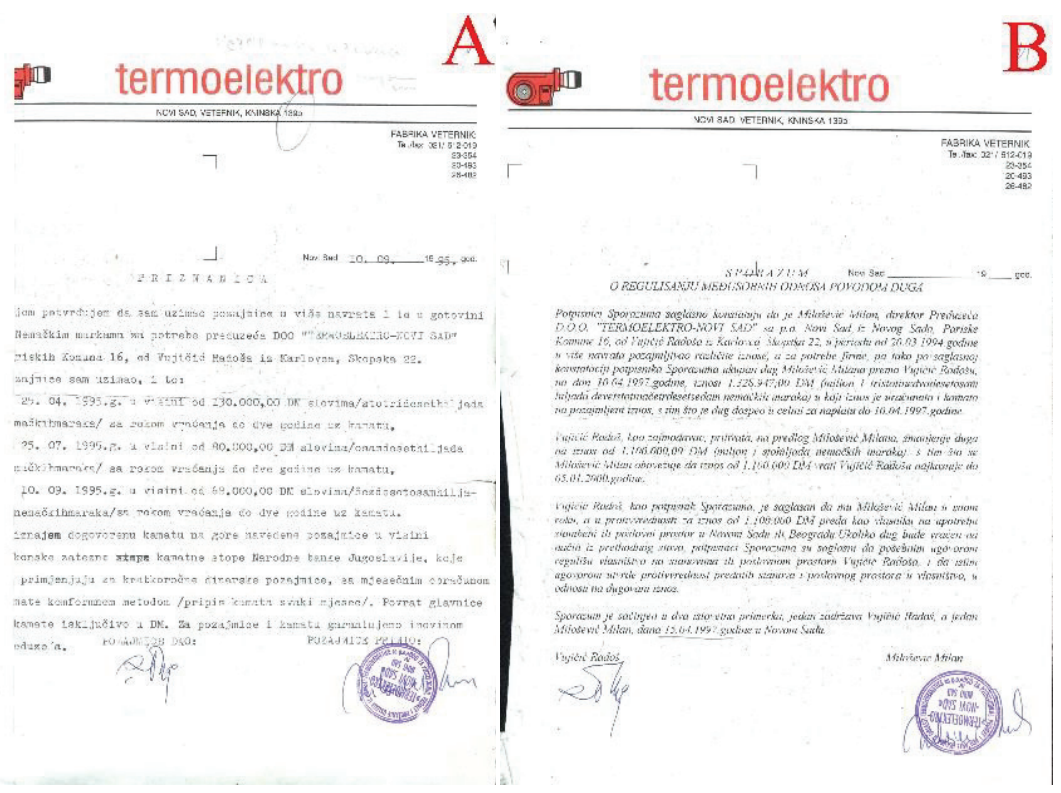

Figure 1. General layout of the document: the receipt (A) and the agreement (B)
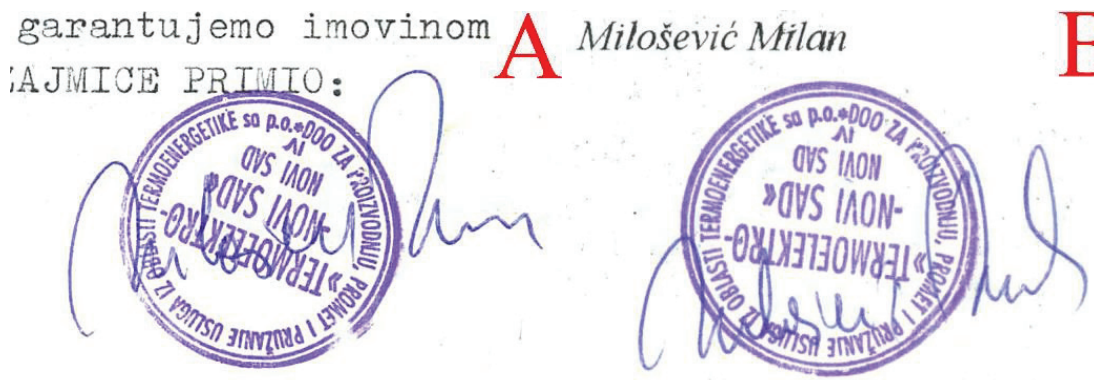

Figure 2. Closer look on the company owner's signature with a stamp impression: in the receipt (A) and the agreement (B)

the same three identification characteristics, which represent the unquestionable proof that they were made with the same stamp.

All the features mentioned above are shown in Figure 3 where one of the characteristics appearing in both impressions looks like long drop in 
the last letter "O" in the word "TERMOELEKTRO," marked by number 1 . Second one is a light triangle-shaped area with a small dot on the inside rim of the outer circle, marked with a number 2, while the third one is represented by a blur and insufficiently clear lines of the upper parts of the joined capital letters "PR" in the word "PROIZVODNJU," marked by a number 3 .

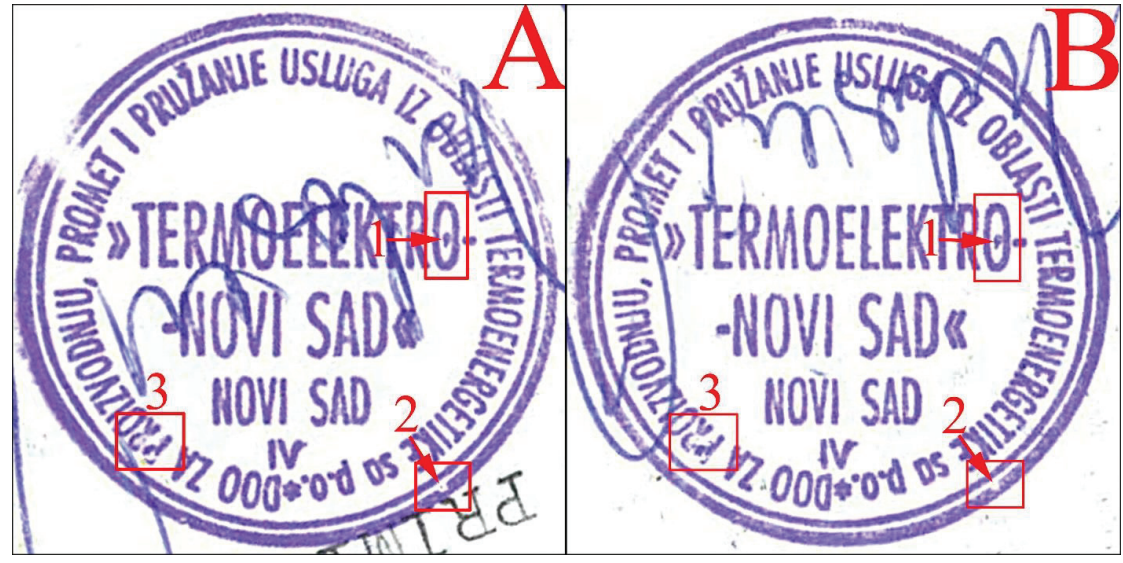

Figure 3. Comparative overview of the stamp impressions in the questioned receipt ("A") and questioned agreement ("B"). Joint characteristics of both impressions are marked with the numbers 1,2 , and 3

With the aim to determine the real time when the two questioned documents were made, the non-questioned documents from the company records were used as a base of unquestioned documents used for comparison. Since during the visual analysis of the numerous original copies of the documents from the company records not a single document written on the typewriter was found, nor one typed on a personal computer in italics, determining the exact time when the two questioned documents were made was based exclusively on optic comparative analysis of the stamp impressions in the questioned documents and the ones from the records. For that purpose, the original copies of the documents containing the stamp impression, ink color, and other general characteristics resembling the ones in the questioned documents were taken out of the records. Since the questioned receipt was dated 10.09.1995 and the questioned 
agreement 15.04.1997, for the purposes of comparative analysis all the documents dated 1995, 1996, and 1997 that contained stamp impressions were taken out of the records.

Fifteen documents from the records dated from 10.04.1997 to 9.05.1997 contained stamp impressions with the identification characteristics marked by number 1 . This can be seen in Figures 4 and 5 which, due to their size, were not put together into a single photo, but the documents with stamp impressions are shown in date order.

In the displayed line of the stamp impressions from the records, starting on 10.04.1997 and ending on 9.05.1997, we can notice the gradual formation of the described identification characteristics and their repetition through all the impressions until 9.05.1997, when they suddenly disappear and are no longer present in further documents.
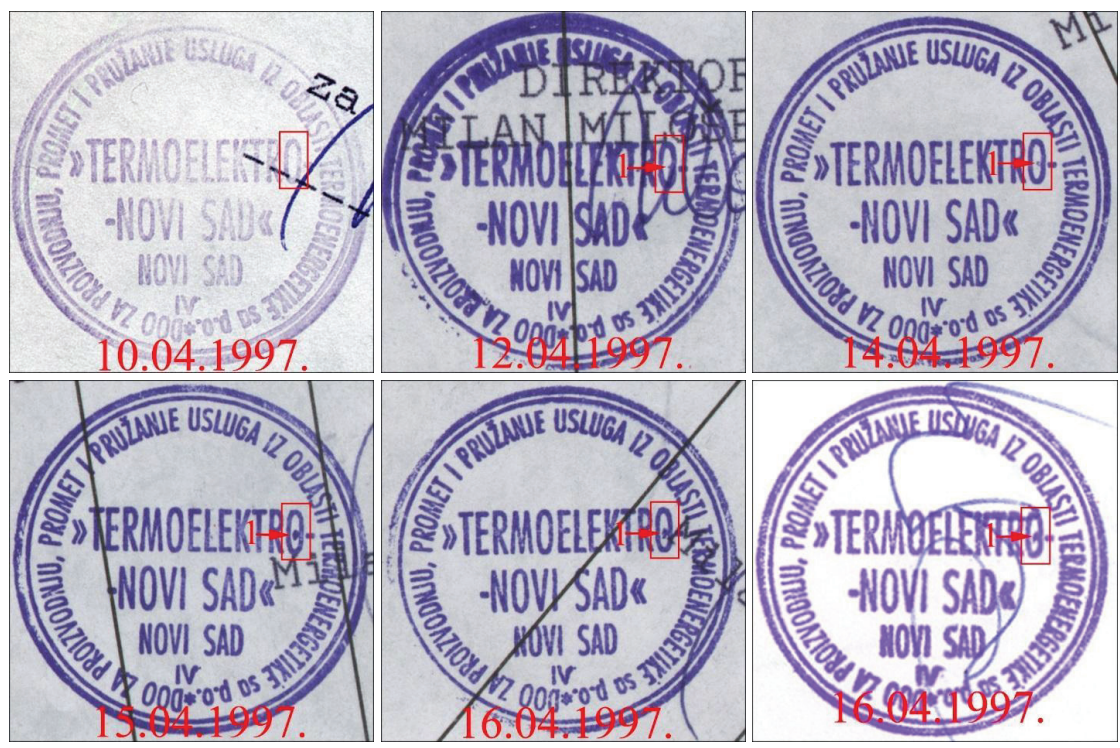

Figure 4 


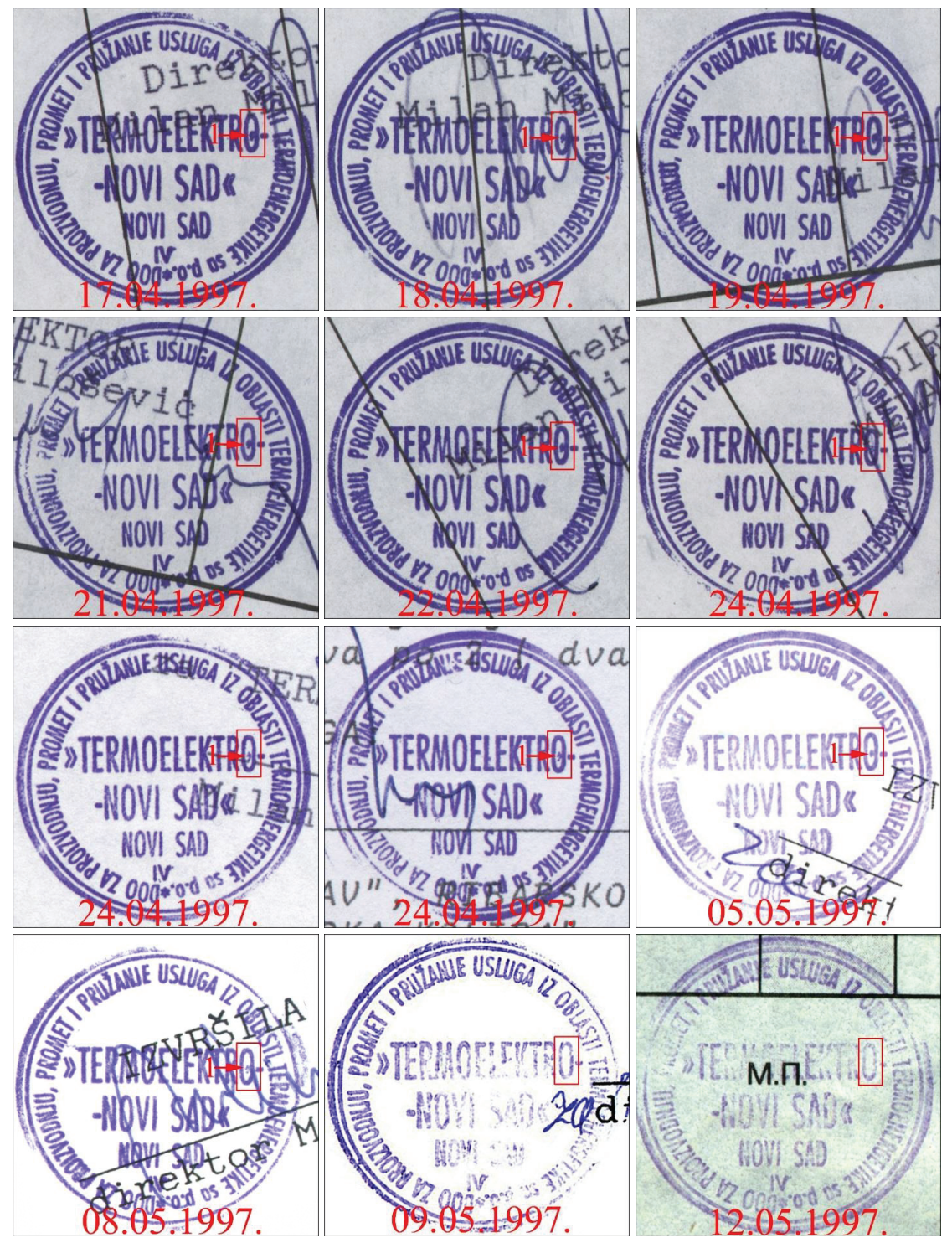

Figure 5

Nowa Kodyfikacja Prawa Karnego 60, 2021

(C) for this edition by CNS 
The appearance as well as the disappearance of this identification characteristic can be explained by the gradual gathering of grains and/or speck of dust within the relief letter "O" in the stamp, possibly from the dirty surface of the ink pad which led to forming a temporary lump which at one point just fell off the stamp.

It is therefore obvious that the questioned receipt, dated 10.09.1995, as well as questioned agreement, dated 15.04.1997, were issued between 12.04.1997 and 9.05.1997.

Since the identification characteristic marked as number 1 in the stamp impressions on the questioned documents is the most similar to identification characteristics of the stamp impressions on the documents in the company records dated from 15.04.1997 to 24.04.1997, by its place, shape, and size we can conclude with the high level of certainty that this time frame represents the real time of creation of both these questioned documents.

On the other hand, bearing in mind that both stamp impressions in the questioned documents are of the same purple color as well as that none of the stamp impressions in the documents from the company's records had identification characteristics marked as number 2 and 3, it can be concluded that in both these documents they were made exclusively as a consequence of uneven application of ink on the surface of a stamp which made the impressions. Thus, it can be concluded that both impressions were made at the same time, by consecutive stamp impressions without repeated ink application on its relief surface.

\section{Case number 2}

In year 2006, the court of law demanded an expert's analysis in order to determine whether the questioned document - annex to the contract number 1, dated 28.03.1996, was made on that date, and if not, when it was actually made.

The questioned annex to the contract number 1 was made on a memorandum of a wholesale and retail, export and import company called Varošanka between the mentioned company and one called Mobex, in which, apart from the text typed on a typewriter, there were also the signature of the directors and stamps of both companies. Figure 6 displays the original copy of the questioned annex, as well as the stamp impression of the Varošanka company in the annex. 
Since the questioned annex was made on the memorandum of company Varošanka, their records were used to determine the time of its creation. When the records were inspected, it was determined that all the documents typed on a typewriter since the time when the company was founded in 1986 until the inspection date on 9.11.2006 were written on a different typewriter than the questioned annex. This led to the conclusion that the date of the annex creation can be determined only based on the stamp impression.
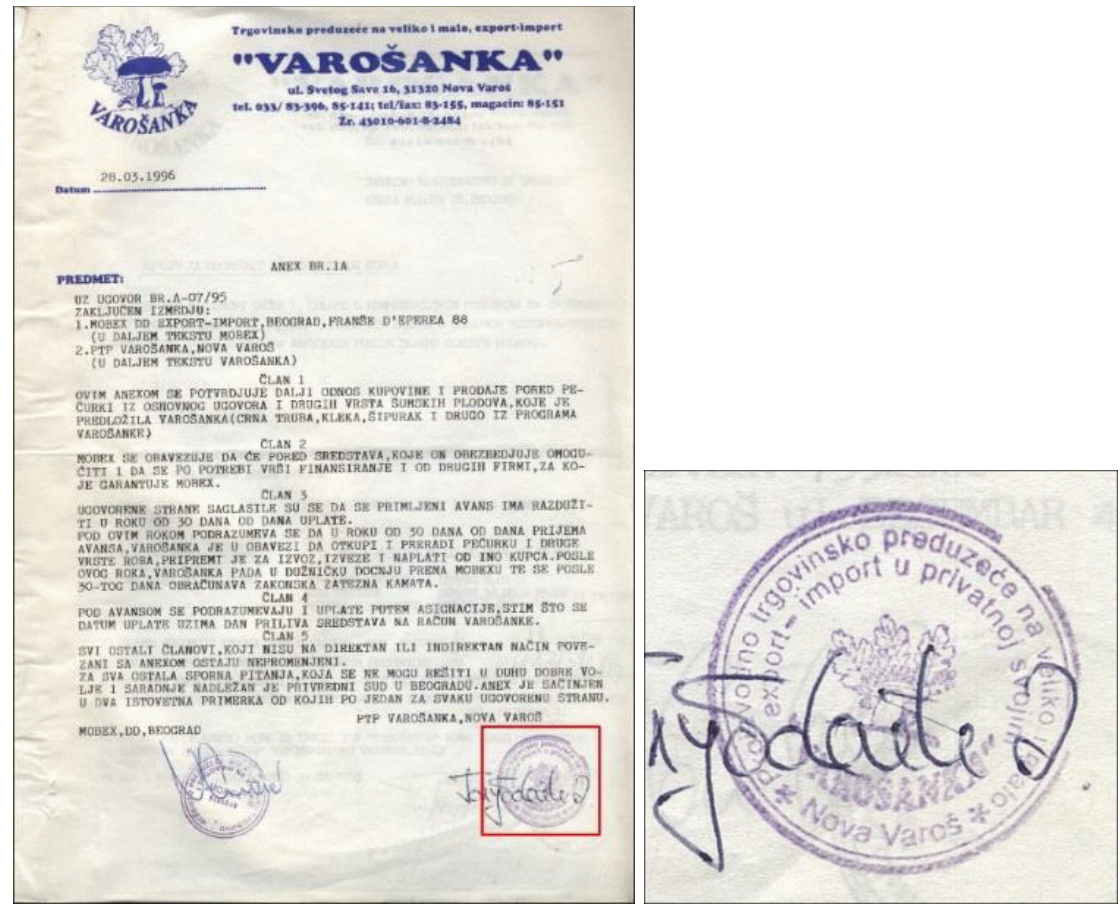

Figure 6

General characteristics of the impression in the mentioned annex are its purple color, round shape, size, as well as the disposition, shape and size of the content elements. The impression also had damage which was clearly visible gaps in the outer rim, as well as dotted blurs in upper part of the penultimate letter "e" of the word "preduzeće," which can be ob- 
served in Figure 7 where the mentioned signs of damage are marked by numbers 1,2 , and 3 .

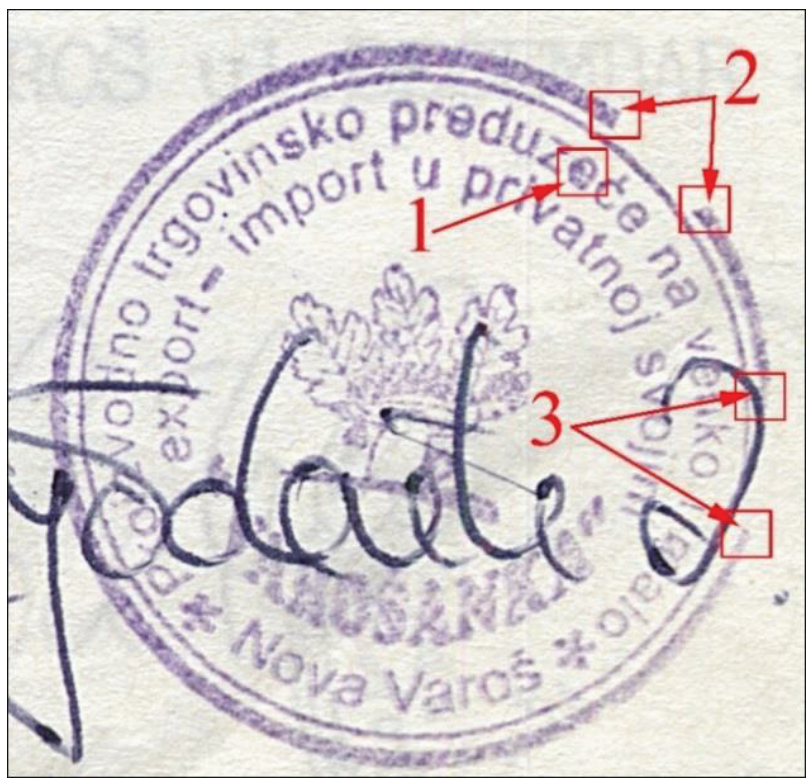

Figure 7

Taking into consideration that this damage of a stamp impression in the questioned annex dated 28.03.1996 can represent identification characteristics of the impression suitable for the exact determination of time of its creation, all the original copies of the documents with the stamp impressions of the same general characteristics were taken from Varošanka's records for the period from 19.03.1996 to 16.10.1997. After that date there was no document with the same impression in the records - since the company was re-registered on 18.10 .1997 , the stamp was not valid anymore and it was destroyed.

However, during the comparative optical analysis of the mentioned stamp impression from the questioned annex and the stamp impressions from the documents taken from the company records, it was determined that there are only four documents dated within the period from 19.03.1996 to 12.04.1996, including the one dated 28.03.1996 mentioned 
in the questioned annex, which had none of the three signs of damage. This is displayed in Figure 8 where there are stamp impressions from the questioned annex and the mentioned four documents from the company records. The stamp impression from the questioned annex is marked by letter A; the one from the document dated 19.03.1996 is marked by letter B; the one from 21.03.1996 by letter C, from 5.04 .1996 by letter $\mathrm{D}$, and from 12.04.1996 by letter $\mathrm{E}$.
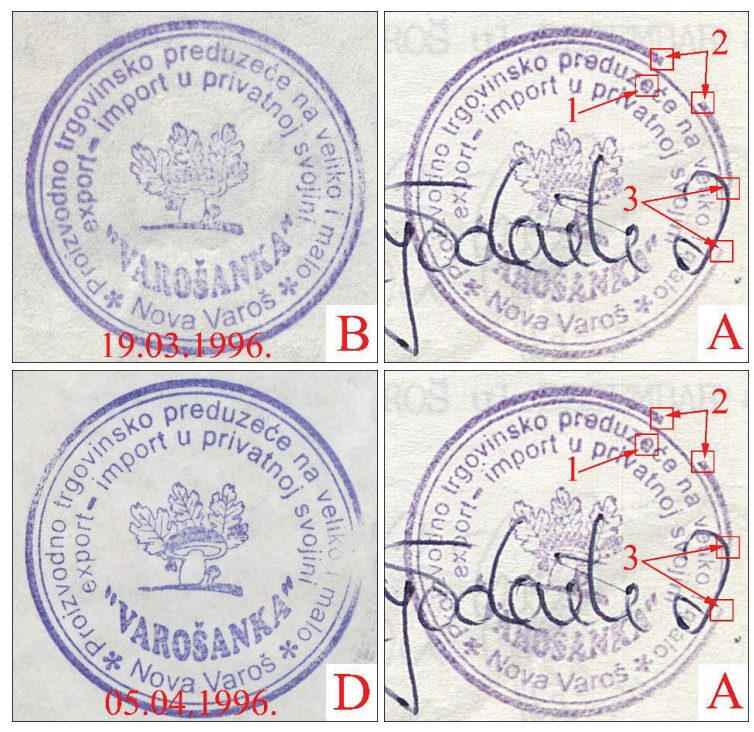
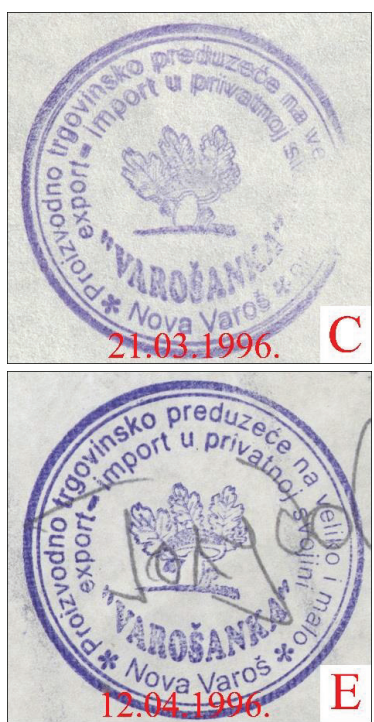

Figure 8

During the further comparative analysis, however, a document dated 1.10.1997 was found in the company records, bearing a stamp impression with all the three signs of damage visible in the questioned annex, as well as the same general characteristics and the same color. Because of their reoccurrence in both impressions, these losses have the status of identification characteristics which undoubtedly imply that they were made by the same stamp.

This is displayed in Figure 9, where the stamp impression in the questioned annex is marked by letter $\mathrm{A}$, the one from the document from the records from 1.10 .1997 by letter $F$, and the one from the records dated 16.10.1997 by letter $\mathrm{G}$. 


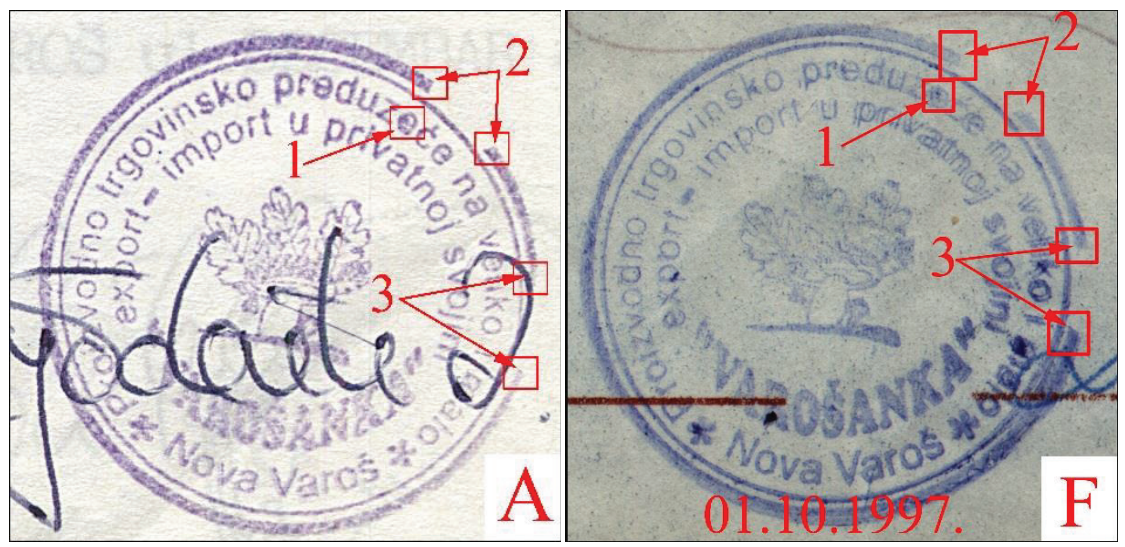

Figure 9

In the next and at the same time the last impression of the same stamp from the records, dated 16.10.1997, the change of the fault marked by number 3 can be observed, which does not exist as such anymore. One end of the broken line ends at the height of the small letter "e" in the word "veliko," while in the impression in the document from 1.10 .1997 it ends at the height of the small letter "i" of the same word. This can be observed in Figure 10, which presents stamp impressions on the mentioned documents, marked by letters $\mathrm{F}$ and $\mathrm{G}$, with the dates.

The gradual appearance of all three signs of damage can be observed in the stamp impressions during the period from 17.07.1997 to 1.10.1997, which is displayed in Figure 11 with a line of stamp impressions along with the dates when they were made.

The damage marked by numbers 2 and 3 is clearly formed as a consequence of the stamp's outer relief rim erosion, while the fault marked by number 1 is made as a consequence of the grains and traces stuck in the relief small letter "e" within the stamp.

With all the aforementioned data, it is clear that the questioned annex to the contract was not made on 28.03.1996 as it is stated, and that the real time of its creation is in the period between 18.09.1997 and 16.10.1997. 


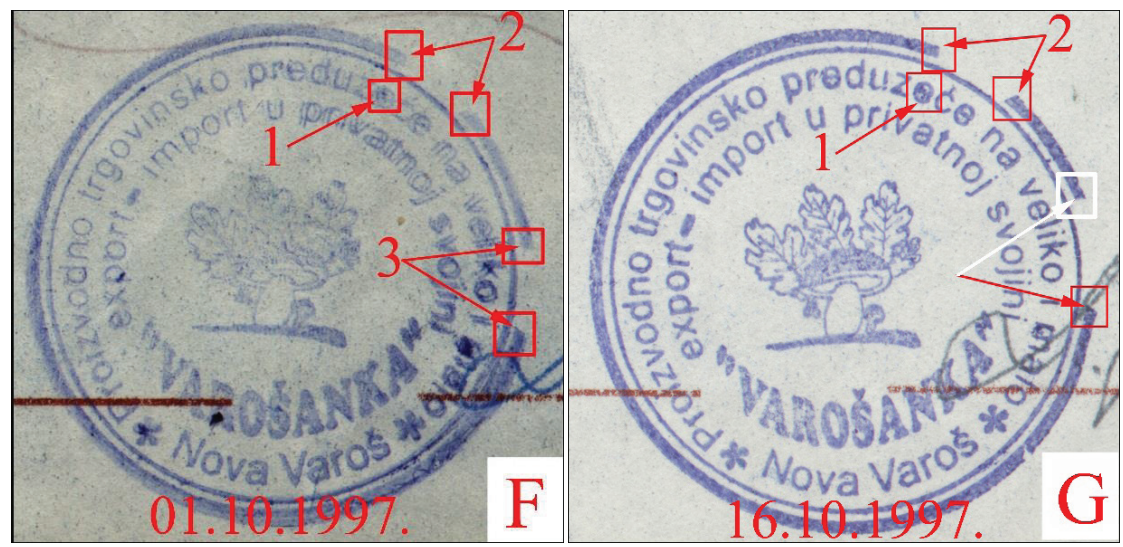

Figure 10
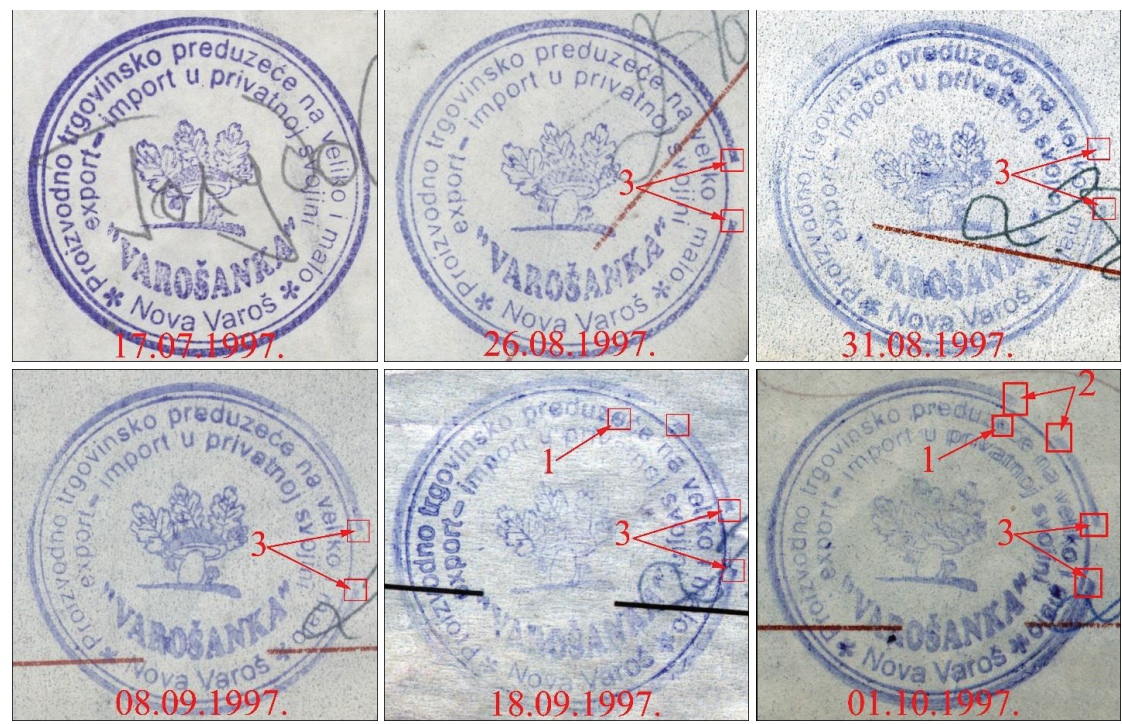

Figure 11

Case number 3

In one criminal proceeding in the year 2012, a court of law demanded expert analysis on the certificates of one company. It should have been 
determined if the certificates from the company for trade and services called Integra Motors were issued at the same time or at the times stated in them. One was dated 18.10.2004 and the other 7.12.2004.

Both certificates were made on the memorandum of the company and contained printed text from the PC printer, a signature by the same employee, and the company stamp. General characteristics of both documents are displayed in Figure 12, where the certificate from 18.10.2004 is marked by letter A and the one from 7.12.2004 by letter B.

Since there were no other possibilities, the analysis whether the questioned certificates were made at the same time was based on the stamp impressions. Comparative optical analysis of both the original copies led to the conclusion that their general characteristics, such as shape and size, as well as the disposition, shape, and size of the certain content elements are matched. It is also determined that they have one mutual, clearly visible, pin-shaped microscopic identification characteristic (although not of the same size), which can be observed at the same place in both impressions: on the line of the letter "O" in the word "BEOGRAD." This, among other things, implies that the impressions were made by the same stamp. This is all displayed in Figures 13 and 14.

Original copies of the documents with stamp impressions matching the impressions in the questioned certificates in terms of general characteristics were taken from the company records for comparison.

During the comparative optical analysis of the stamp impressions in the questioned certificates and the impressions of the same stamp in the documents taken from the company records, four documents were found to have the same date as the questioned certificates. However, none of those impressions had the described identifying characteristic. Additionally, after 7.12.2004, in the company records there was no document with the required stamp impression, since it was not valid after that date - it was destroyed on 20.06.2005 and, along with two other company stamps, proclaimed invalid.

The stamp impressions in the four mentioned documents from the company records are displayed according to their dates of creation in Figures 15 and 16 and marked by letters C, D, E, and F. 


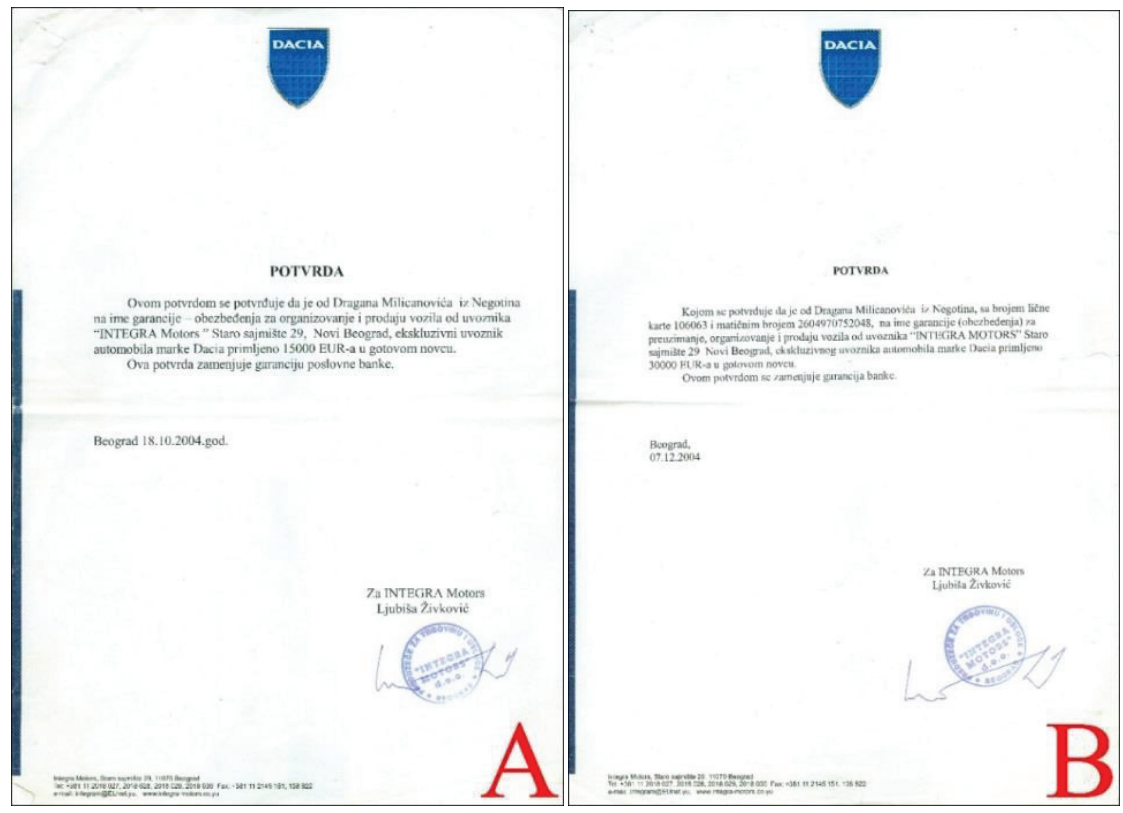

Figure 12

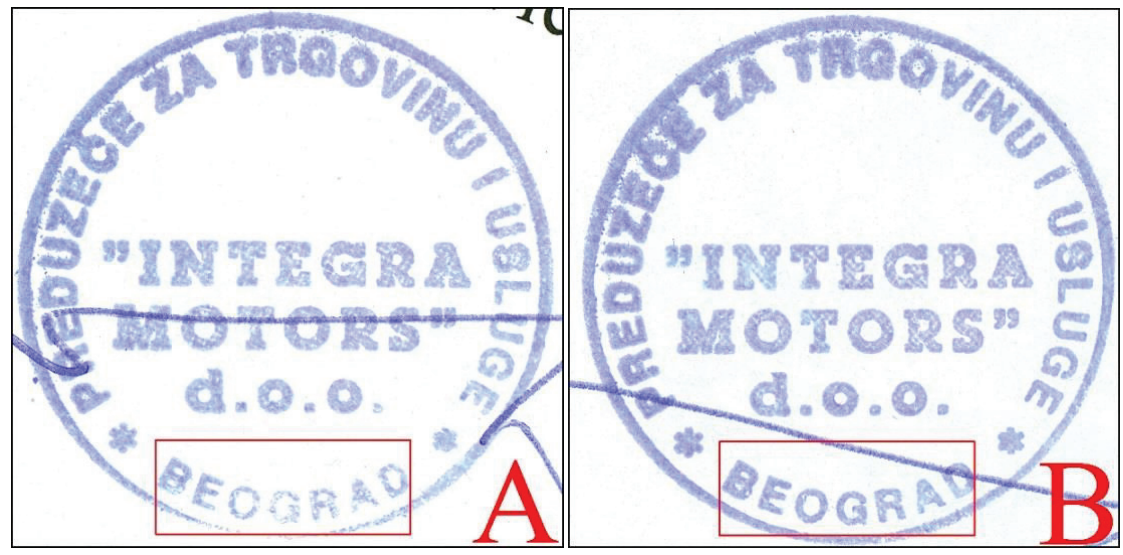

Figure 13 


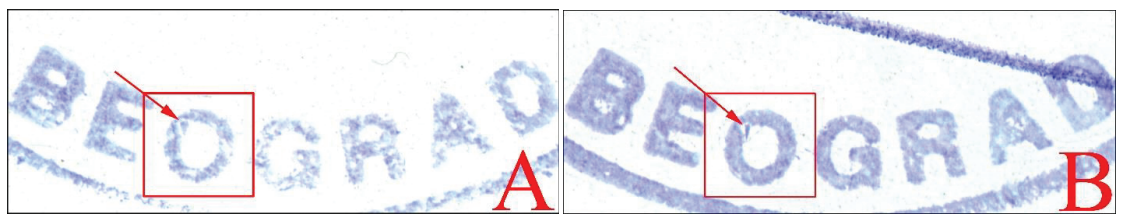

Figure 14

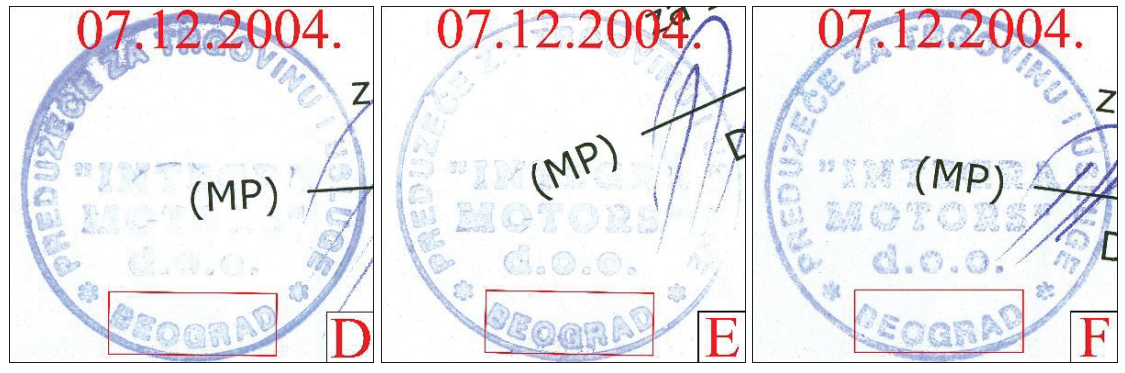

Figure 15

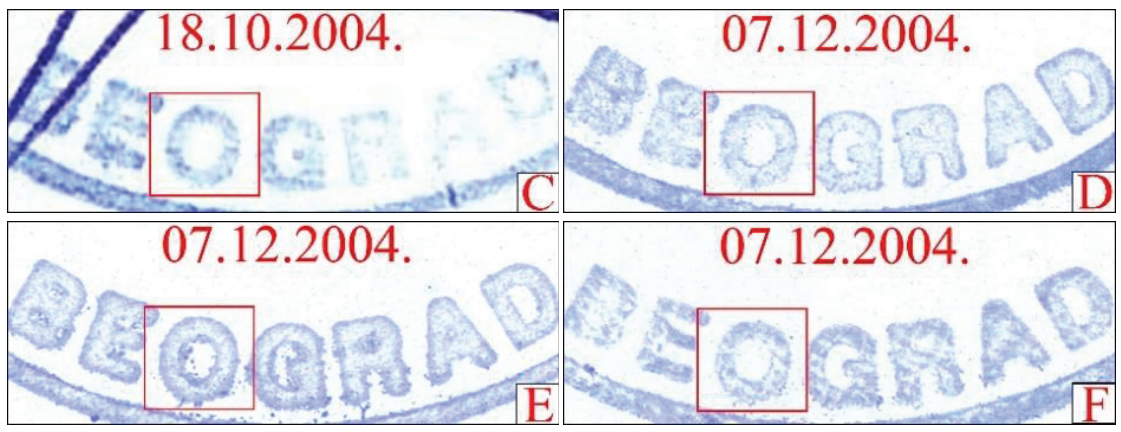

Figure 16

Since none of the impressions in the documents from the company records which are dated within the period stated in the questioned certificates contain identifying characteristics visible in the stamp impressions from the two questioned certificates, it is obvious that they were not made at the time stated in them. 
If the described identifying characteristics of the stamp impressions in the questioned certificates were created as a consequence of a temporarily stuck grain or trace of a certain materia ${ }^{16}$ on a relief edge of the mentioned letter "O" within the stamp, it is possible that both certificates were made at the same time.

However, if the mentioned identifying characteristics were made as a consequence of physical damage to the mentioned letter's relief edge within the stamp, then both certificates could have been made only between 7.12.2004, when it was not valid, and 20.06.2005, when it was destroyed by the committee.

It was impossible to determine whether it was the case of a temporarily stuck grain or trace of a material or physical damage, since the stamp which made the impressions does not exist anymore.

\section{Conclusion}

Determination of the document's age (absolute and relative) always represents a challenge for an expert. In the practice of forensic expert Miroslav Busarčević, the method for determining age based on the comparison of stamp impressions in the questioned document and documents with the impressions of the same stamp in the documents from the company's authentic records has proven to be highly successful. This method includes scanning questioned and authentic documents in high resolution, analysing them in any of the Adobe Photoshop programs, finding questioned details in stamp impressions in questioned documents and comparing them with the details of stamp impressions in authentic documents. Unlike expensive physicochemical methods used in attempts to discover the age of documents, this method determines the exact time frame when the questioned document was created. This method is much cheaper and more accessible in everyday work of forensic experts.

16 For example, paper. 


\section{References}

Brunelle R.L., Crawford K.R., Advances in the forensic analysis and dating of writing ink, Springfield, IL 2003.

Bügler J.H., Buchner H., Dallmayer A., "Age determination of ballpoint pen ink by thermal desorption and gas chromatography-mass spectrometry", Journal of Forensic Sciences 53, 2008, no. 4.

Deviterne-Lapeyre C.M., "Interpol review of questioned documents 2016-2019”, Forensic Science International: Synergy 2, 2020.

Ellen D., Day S., Davies C., Scientific examination of documents: methods and techniques, Boca Raton, FL 2018.

Goc M., Miron M., "Examination of the relative age of documents. Part I. Methods of examining the sequence of writing made using different techniques on a paper substrate - general issues", Problemy kryminalistyki (Issues of Forensic Science) 284, 2014, no. 2 .

Gorshkova K.О., “Выявление признаков искусственного старения документов: исследование сигналов флуоресценции оптических отбеливателей с поверхности бумажного носителя" [Identification of signs of artificial aging of documents: study of fluorescence signals of optical brighteners from the surface of a paper carrier], Coвременные тенденции развития науки и технологий Сборник научных трудов по материалам $B$ международной научно-практической конференции, г. Белгород [Modern trends in the development of science and technology: Collection of scientific papers based on the materials of the International scientific and practical conference in Belgorod], 31.08.2015, https://mepk-a.ru/bez-rubriki/vyyavlenie-priznakov-iskusstvennogo/.

Kochemirovskiy V.A. et al., "Age determination of handwritten inscriptions and stamp impressions on documents using Raman spectroscopy and gas chromatography", News of Science. Proceedings of Materials the International Scientific Conference, Czech Republic, Karlovy Vary - Russia, Moscow, 30-31 August 2015, https://mepk-a.ru/bez-rubriki/age-determination-of-handwritten/ (accessed: 29.11.2021).

Kumar R., Kumar V., Sharma V., "Fourier transform infrared spectroscopy and chemometrics for the characterization and discrimination of writing/photocopier paper types: Application in forensic document examinations", Spectrochimica Acta. Part A: Molecular and Biomolecular Spectroscopy 170, 2017.

LaPorte G.M. et al., "The identification of 2-phenoxyethanol in ballpoint inks using gas chromatography/mass spectrometry - relevance to ink dating", Journal of Forensic Science 49, 2003, no. 1.

Lociciro S. et al., "Dynamic of the ageing of ballpoint pen inks: quantification of phenoxyethanol by GC-MS", Science \& Justice: Journal of the Forensic Science Society 44, 2004, no. 3.

Ortiz-Herrero L. et al., "Direct and indirect approaches based on paper analysis by PyGC/MS for estimating the age of documents", Journal of Analytical and Applied Pyrolysis 131, 2018. 
Ouyang G.et al., "Preliminary studies on the absorbance ratio method used to determining the age of stamp-pad ink seal", Journal of Forensic Sciences 64, 2019, no. 4.

Scientific examination of questioned documents, eds. J.S. Kelly, B.S. Lindblom, Boca Raton, FL 2006.

Silva C.S. et al., "Chemometric approaches for document dating: Handling paper variability”, Analytica Chimica Acta 1031, 2018.

Skoromnikova O.A., Yurova R.A., Stepanenko E.А., “Актуальные проблемыприменения методики «Определение давности выполнения реквизитов в документах по относительному содержанию в штрихах летучих растворителей»" (Ongoing issues with the use of the ink dating methodology based on relative content of volatile solvents in document entries)", Теория и практика судебной экспертизы (Theory and Practice of Forensic Science) 13, 2018, no. 3.

Weyermann C., Spengler B., "The potential of artificial aging for modelling of natural aging processes of ballpoint ink", Forensic Science International 180, 2008.

Zięba-Palus J. et al., "Analysis of degraded papers by infrared and Raman spectroscopy for forensic purposes", Journal of Molecular Structure 1140, 2017. 